\title{
Dynamic Characteristics of the Hippocampal Neuron under Conductance's Changing
}

\author{
Yueping Peng \\ Engineering College of Armed Police Force, 710086, Xi'an, China \\ Email: percy001@163.com \\ Nan Zou \\ Engineering College of Armed Police Force, 710086, Xi’an, China \\ Email: percy001@sina.com \\ Haiying $\mathrm{Wu}$ \\ Engineering College of Armed Police Force, 710086, Xi'an, China \\ Email: percy7402@sohu.com
}

\begin{abstract}
The hippocampal CA1 pyramid neuron has plenty of discharge actions. In the thesis, the dynamic characteristics of the hippocampal neuron model are analyzed and discussed by the neurodynamic theory and methods. Under a certain amplitude current's stimulation, the change of $g_{\mathrm{Na}}$ (the maximum conductance of the transient sodium channel) and $g_{K d r}$ (the maximum conductance of the delay rectification potassium channel) can cause different dynamic characteristics of the neuron model. The transient $\mathrm{Na}^{+}$current $\left(I_{N a}\right)$ caused by $g_{N a}$ is indispensable in the discharge's formation process of the model. The model can generate the discharge process only when $g_{N a}$ reaches a certain threshold. In the discharge process of the neuron model, $g_{N a}$ 's changing affects little and the ISIs approximate to a straight line. The delay rectification $\mathbf{K}^{+}$current $\left(I_{K d r}\right)$ caused by $g_{K d r}$ isn't indispensable in the discharge's formation process of the model. But $g_{K d r}$ 's changing affects much in the discharge process of the neuron model. With $g_{K d r}$ 's changing, the neuron model undergoes different dynamic bifurcation process, and has plenty of discharge patterns such as the chaos, period, and so on. This investigation is helpful to know and investigate the dynamic characteristics and the bifurcation mechanism of the hippocampal neuron; and it provides a certain theory assist to investigate the neural diseases such as the Alzheimer disease by neurodynamics.
\end{abstract}

Index Terms-neuron, neurodynamics, conductance

\section{INTRODUCTION}

In the 1990s, neuron modeling in hippocampal region

The corresponding author is Yueping Peng. has been becoming the research hotspot in the field of neural science. Depended on electrophysiological experiments and new technologies such as optics imaging, some models of hippocampal pyramidal Neuron based on ionic conductance have been successfully constructed; The work of R.D.Traub's research team is the most excellent [1-20]. In 1991, based on the electrophysiological experiment data of Guinea pig hippocampal neurons, R.D.Traub had developed a 19compartment cable model of CA3 pyramidal neuron; Based on the model, R.D.Traub's research team had deeply studied these issues such as hippocampal neuronal network, EEG rhythm, plasticity of hippocampal neuron Synapse, electrical coupling influence on hippocampal neuron's high frequency oscillation, and cortical neuron's rapid oscillation[8-10]. Based on R.D.Traub research team's returns and the electrophysiological experiment data, Warman had developed a 16-compartment cable model of CA1 pyramidal neuron based on ionic conductance by computer simulation, and had successfully simulated electrophysiological features and experimental results of CA1 pyramid neuron[11].

The hippocampal CA1 pyramid neuron has plenty of discharge actions. Yue found that bursting behavior persists in adult CA1 pyramidal cells after almost complete truncation of the apical dendrites. The mechanism of bursting is different from the "ping-pong" mechanism, which depends on the integrity of apical dendrites[12-14]. Based on the CA1 pyramidal neuron's membrane ionic channel theory and its electrophysiological experimental data, according to the basic frame of $\mathrm{H}-\mathrm{H}$ class model, David had developed one-compartment model of CA1 Pyramidal Neuron by neurodynamic theory[15]. The model is different from former multi-compartment cable models of the hippocampal pyramid neuron. This model omits the effects of the apical dendrites and the complexity is reduced, which not only can simulate many 
electrophysiological features and experimental results of the hippocampal CA1 pyramid neuron, but also can spontaneously generate regular firing, tonic firing, rhythmic bursting, and so on.

In this study, we take the nine-dimension onecompartment complex model of CA1 pyramid neuron developed by David as the object, and analyze and discuss the model's dynamic characteristics by the neurodynamic theory[21-25] and methods.

\section{The Nine-Dimension Model of CA1 Pyramid NEURON AND ITS DisCHARGE PATTERNS}

The nine-dimension one-compartment model of CA1 pyramid neuron developed by David has multiple time scale dynamic action. The current balance equation of the model is as follows:

$C \frac{d V}{d t}=-I_{L}-I_{N a}-I_{N a P}-I_{K d r}-I_{A}-I_{M}-I_{C a}-I_{Y}-I_{\text {sAHP }}+I_{A p p}$

Where $\mathrm{C}$ is the membrane capacitance; $\mathrm{V}$ is the membrane potential; $\mathrm{I}_{\mathrm{L}}$ is the leakage current; $\mathrm{I}_{\mathrm{Na}}$ is the transient $\mathrm{Na}^{+}$current; $\mathrm{I}_{\mathrm{NaP}}$ is the persistent $\mathrm{Na}^{+}$current; $\mathrm{I}_{\mathrm{Kdr}}$ is the delay rectification $\mathrm{K}^{+}$current; $\mathrm{I}_{\mathrm{A}}$ is the A-type instantaneous $\mathrm{K}^{+}$current; $\mathrm{I}_{\mathrm{M}}$ is the muscarine-sensitive $\mathrm{K}^{+}$ current; $\mathrm{I}_{\mathrm{Ca}}$ is the high-threshold $\mathrm{Ca}^{2+}$ current; $\mathrm{I}_{\mathrm{y}}$ is the fast $\mathrm{Ca}^{2+}$-activated $\mathrm{K}^{+}$current; $\mathrm{I}_{\mathrm{AHP}}$ is the slow $\mathrm{Ca}^{2+}$ activated $\mathrm{K}^{+}$current; $\mathrm{I}_{\mathrm{APP}}$ is the stimulation current.

Currents of above balance equation are changed into their corresponding ionic conductance forms, and the eight corresponding time variables are also added. Therefore, the models are changed into set of ninedimension ordinary differential equations,

$$
\begin{aligned}
& C \frac{d V}{d t}=-g_{L}\left(V-V_{L}\right)-g_{N a} m_{\infty}^{3}(V) h\left(V-V_{N a}\right) \\
&-g_{N a P} p_{\infty}(V)\left(V-V_{N a}\right)-g_{K d r} n^{4}\left(V-V_{K}\right) \\
&-g_{A} a_{\infty}^{3}(V) b\left(V-V_{K}\right)-g_{M} z\left(V-V_{K}\right) \\
&-g_{C a} r^{2}\left(V-V_{C a}\right)-g_{y} d_{\infty}\left(\left[C a^{2+}\right]_{i}\right) y\left(V-V_{K}\right) \\
&-g_{\text {SAHP }} q\left(V-V_{K}\right)+I_{A p p} ; \\
& \frac{d h}{d t}= \frac{h_{\infty}(V)-h}{\tau_{h}(V)} ; \\
& \frac{d n}{d t}=\frac{n_{\infty}(V)-n}{\tau_{n}(V)} ; \\
& \frac{d b}{d t}=\frac{b_{\infty}(V)-b}{\tau_{b}} ; \\
& \frac{d z}{d t}=\frac{z_{\infty}(V)-z}{\tau_{z}} ; \\
& \frac{d r}{d t}=\frac{r_{\infty}(V)-r}{\tau_{r}} ; \\
& \frac{d y}{d t}=\frac{y_{\infty}(V)-y}{\tau_{y}} ;
\end{aligned}
$$

$$
\begin{gathered}
\frac{d q}{d t}=\frac{q_{\infty}\left(\left[C a^{2+}\right]_{i}\right)-q}{\tau_{q}} ; \\
\frac{d\left[C a^{2+}\right]_{i}}{d t}=-v g_{C a} r^{2}\left(V-V_{C a}\right)-\frac{\left[C a^{2+}\right]_{i}}{\tau_{C a}} ;
\end{gathered}
$$

The equation model has nine time variables: the membrane potential variable $\mathrm{V}$, transient $\mathrm{Na}^{+}$current inactivation variable $h$, delayed rectified $\mathrm{K}^{+}$current activation variables $\mathrm{n}$, A-type instantaneous $\mathrm{K}^{+}$current inactivation variables $\mathrm{b}$, muscarine-Sensitive $\mathrm{K}^{+}$currentactivated variables $\mathrm{Z}$, high-threshold $\mathrm{Ca}^{2+}$ currentactivated variable $\mathrm{r}$, fast $\mathrm{Ca}^{2+}$-activated $\mathrm{K}^{+}$currentactivated variable $\mathrm{y}$, slow $\mathrm{Ca}^{2+}$-activated $\mathrm{K}^{+}$currentactivated variable $\mathrm{q}$, and intramembrane calcium ion concentration variable $\left[\mathrm{Ca}^{2+}\right]$ i. At numerical calculation, the values of model parameters refer to appendix A. In addition, the state variable of the model is $(\mathrm{V}, \mathrm{h}, \mathrm{n}, \mathrm{b}, \mathrm{z}, \mathrm{r}$, $\left.\mathrm{y}, \mathrm{q},\left[\mathrm{Ca}^{2+}\right] \mathrm{i}\right)$, and the initial state of the model is $(-65,0.1$, $0.1,0.1,0.1,0.1,0.1,0.1,0.05$ ).

The nine-dimension model of CA1 pyramid neuron showed by formula (1) can spontaneously generate regular firing, tonic firing, rhythmic bursting, and so on[15]. Based on MATLAB simulation methods, several common discharge patterns of the nine-dimension model of CA1 pyramid neuron under different currents' stimulation are showed in Figure 1.
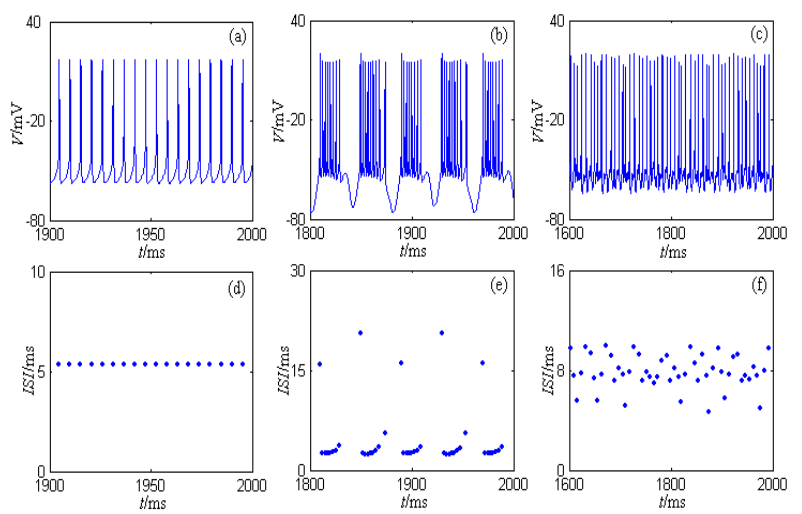

Figure 1. Discharge patterns of the nine-dimension model of CA1 pyramid neuron. (a) and (d) are the period 1 discharge pattern. (b) and (e) are the bursting discharge pattern. (c) and (f) are the chaos discharge pattern.

\section{STUDY ON DYNAMIC CHARACTERISTICS OF THE CA1 Pyramid Neuron Model}

The hippocampal CA1 pyramid neuron has plenty of discharge actions. The nine-dimension model's dynamic characteristics are discussed in the following, and at numerical calculation the values of model's parameters are showed in appendix A.

There are all kinds of voltage or ligand gating ionic channels such as potassium channel, calcium channel, sodium channel in the membrane of hippocampal pyramid neuron. The transient $\mathrm{Na}^{+} \operatorname{current}\left(I_{N a}\right)$ and the delay rectification $\mathrm{K}^{+}$current $\left(I_{K d r}\right)$ widely exist in all kinds of neurons, which also pay an important role in the 
discharge process of the neuron model described by formula (1). In the following, the dynamic characteristics of the neuron model described by formula (1) are discussed when the maximum conductance's of the transient $\mathrm{Na}^{+}$current and the delay rectification $\mathrm{K}^{+}$ current are changed.

\section{A. Dynamic Characteristics under $g_{\mathrm{Na}}$ 's Changing}

The stimulation current is $10 \mathrm{nA}$. The range of $g_{N a}$ (the maximum conductance of the transient sodium channel) is $0 \sim 100 \mathrm{mS} / \mathrm{cm}^{2}$, and the changing step is $0.1 \mathrm{mS} / \mathrm{cm}^{2}$. The simulation time is $0 \sim 2000 \mathrm{~ms}$, and ISI's graphing time interval is $1000 \sim 2000 \mathrm{~ms}$. Fig.2 shows the ISI bifurcation figure of the neuron model under $g_{\mathrm{Na}}$ 's Changing.

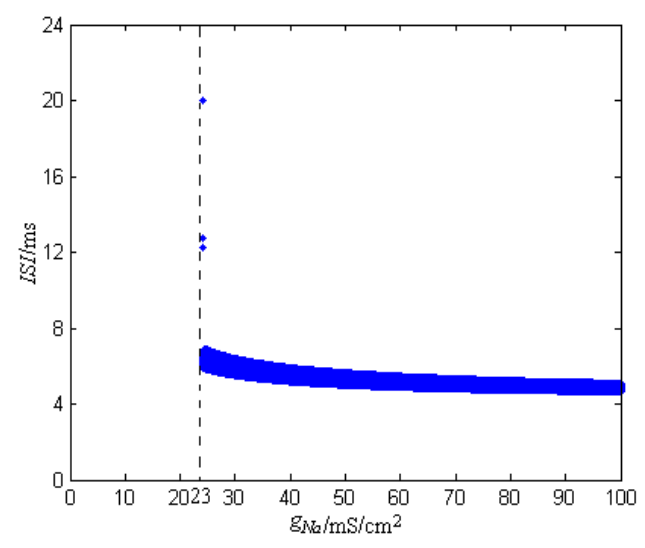

Figure 2. The ISI bifurcation figure of the neuron model under $\boldsymbol{g}_{\mathrm{Na}}$ 's Changing.

From Fig.2, for the neuron model described by formula (1), it can generate the discharge process only when $g_{\mathrm{Na}}$ (the maximum conductance's of the transient sodium channel) reaches a certain threshold (about $23 \mathrm{mS} / \mathrm{cm}^{2}$ ). So in the discharge's formation process of the model, $g_{N a}$ is indispensable. But $g_{N a}$ 's changing affects little in the discharge process of the neuron model, and the ISIs approximate to a straight line; That is to say, the discharge frequency keeps unchanged.

\section{B. Dynamic Characteristics under $g_{K d r}$ 's Changing}

The stimulation current is $10 \mathrm{nA}$. The range of $g_{K d r}$ (the maximum conductance of the delay rectification potassium channel) is $0 \sim 20 \mathrm{mS} / \mathrm{cm}^{2}$, and the changing step is $0.05 \mathrm{mS} / \mathrm{cm}^{2}$. The simulation time is $0 \sim 2000 \mathrm{~ms}$, and ISI's graphing time interval is 1000 2000ms. Fig.3 shows the ISI bifurcation figure of the neuron model under $\boldsymbol{g}_{K d r}$ 's Changing.

From Fig.3, for the neuron model described by formula (1), it can generate the discharge process when $g_{K d r}$ (the maximum conductance's of the transient potassium channel) is $0 \mathrm{mS} / \mathrm{cm}^{2}$. So in the discharge's formation process of the model, $g_{K d r}$ isn't indispensable. But $g_{K d r}$ 's changing affects much in the discharge process of the neuron model. When $g_{K d r}$ is less than $3.2 \mathrm{mS} / \mathrm{cm}^{2}$, the neuron model has plenty of discharge patterns; When $g_{K d r}$ is near $1 \mathrm{mS} / \mathrm{cm}^{2}, 1.6 \mathrm{mS} / \mathrm{cm}^{2}$, $2.5 \mathrm{mS} / \mathrm{cm}^{2}$, and $2.8 \mathrm{mS} / \mathrm{cm}^{2}$, the neuron model's discharge pattern is the chaos, but in other region of $g_{K d r}$, the neuron model's discharge pattern is mainly the period. In addition, the range of ISIs is about $3 \sim 50 \mathrm{~ms}$, and the discharge frequency is wide. When $g_{K d r}$ is near $2.9 \mathrm{mS} / \mathrm{cm}^{2}$, the neuron's discharge pattern evolves from the chaos to period 2; with $g_{K d r}$ 's increasing gradually, the neuron's discharge pattern evolves into period 1 near $3.2 \mathrm{mS} / \mathrm{cm}^{2}$ via the adverse adding period bifurcation. When $g_{K d r}$ is more than $3.2 \mathrm{mS} / \mathrm{cm}^{2}$, the neuron's discharge pattern is period 1 , and the ISIs approximate to a straight line; That is to say, the discharge frequency keeps unchanged.
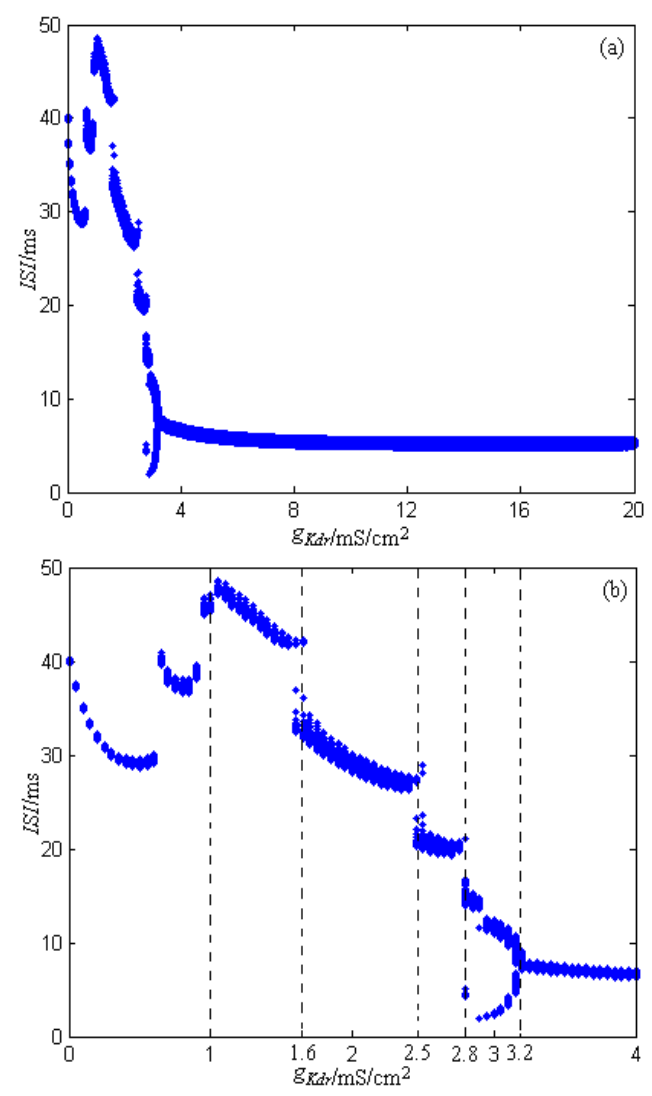

Figure 3. The ISI bifurcation figure of the neuron model under $\boldsymbol{g}_{K d r}$ 's Changing. (a) $g_{K d r}$ is $0 \sim 20 \mathrm{mS} / \mathrm{cm}^{2}$. (b) $g_{K d r}$ is $0 \sim 4$ $\mathrm{mS} / \mathrm{cm}^{2}$.

Fig.4 shows the neuron model's attractors on V-n phase plane under $g_{K d r}$ 's changing, where the stimulation current is $10 \mathrm{nA}$. The simulation time is $0 \sim 2000 \mathrm{~ms}$, and the graphing time interval is 1000 2000ms. 
From Fig.4, When $g_{K d r}$ is $0 \mathrm{mS} / \mathrm{cm}^{2}, 1 \mathrm{mS} / \mathrm{cm}^{2}$, $1.55 \mathrm{mS} / \mathrm{cm}^{2}, 2.8 \mathrm{mS} / \mathrm{cm}^{2}$, and $3.2 \mathrm{mS} / \mathrm{cm}^{2}$, the neuron model's orbits in the phase plane all form the limit cycle, and generate the discharge process, whose discharge patterns are mainly period 1 or the chaos. So $g_{K d r}$ 's changing can make the neuron model to generate many discharge patterns, and have an important impact on the discharge characteristics.
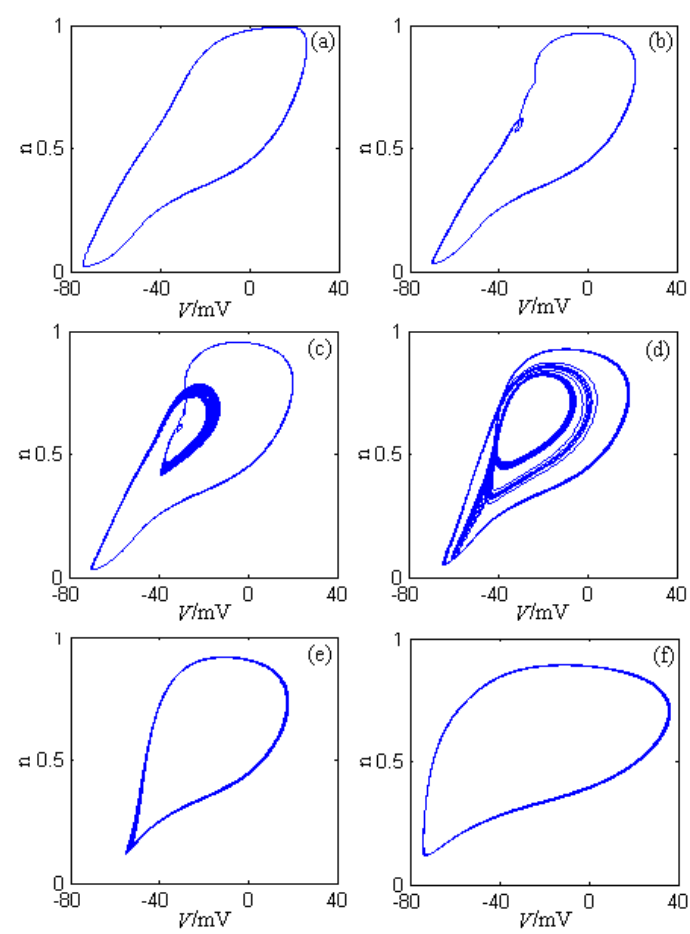

Figure 4. The neuron model's attractors on V-n phase plane under $g_{K d r}$ 's changing. (a) $g_{K d r}=0 \mathrm{mS} / \mathrm{cm}^{2}$. (b) $g_{K d r}=1 \mathrm{mS} / \mathrm{cm}^{2}$. (c) $g_{K d r}=1.55 \mathrm{mS} / \mathrm{cm}^{2}$. (d) $g_{K d r}=2.8 \mathrm{mS} / \mathrm{cm}^{2}$. (e) $g_{K d r}=3.2 \mathrm{mS} / \mathrm{cm}^{2}$. (f) $g_{K d r}=5 \mathrm{mS} / \mathrm{cm}^{2}$.

The neuron model has plenty of discharge patterns under $g_{K d r}$ 's changing. From the angle of neuro dynamics, the neuron model changes from a discharge pattern to another discharge pattern, and in this process the neuron model substantially undergoes the dynamic bifurcation. In order to describe the dynamic bifurcation process clearly, Fig.5 and Fig.6 respectively shows the neuron model's phase plane attractor bifurcation chart when $g_{K d r}$ is near $1.6 \mathrm{mS} / \mathrm{cm}^{2}$ and near $3 \mathrm{mS} / \mathrm{cm}^{2}$, where the stimulation current is $10 \mathrm{nA}$. The simulation time is $0 \sim 2000 \mathrm{~ms}$, and the graphing time interval is 1000 2000ms.

From Fig.5, when $g_{K d r}$ is $1.2 \mathrm{mS} / \mathrm{cm}^{2}$, the neuron model's discharge pattern is period 1 ; With $g_{K d r}$ 's increasing gradually, the neuron model evolves into the chaos discharge pattern via the adding period bifurcation, and goes into the multiply periodic discharge pattern via the adverse adding period bifurcation; At last, the neuron model's discharge pattern becomes period 1 via the adverse adding period bifurcation.

From Fig.5, when $g_{K d r}$ is $1.2 \mathrm{mS} / \mathrm{cm}^{2}$, the neuron model's discharge pattern is period 1 ; With $g_{K d r}$ 's increasing gradually, the neuron model evolves into the chaos discharge pattern via the adding period bifurcation, and goes into the multiply periodic discharge pattern via the adverse adding period bifurcation; At last, the neuron model's discharge pattern becomes period 1 via the adverse adding period bifurcation.
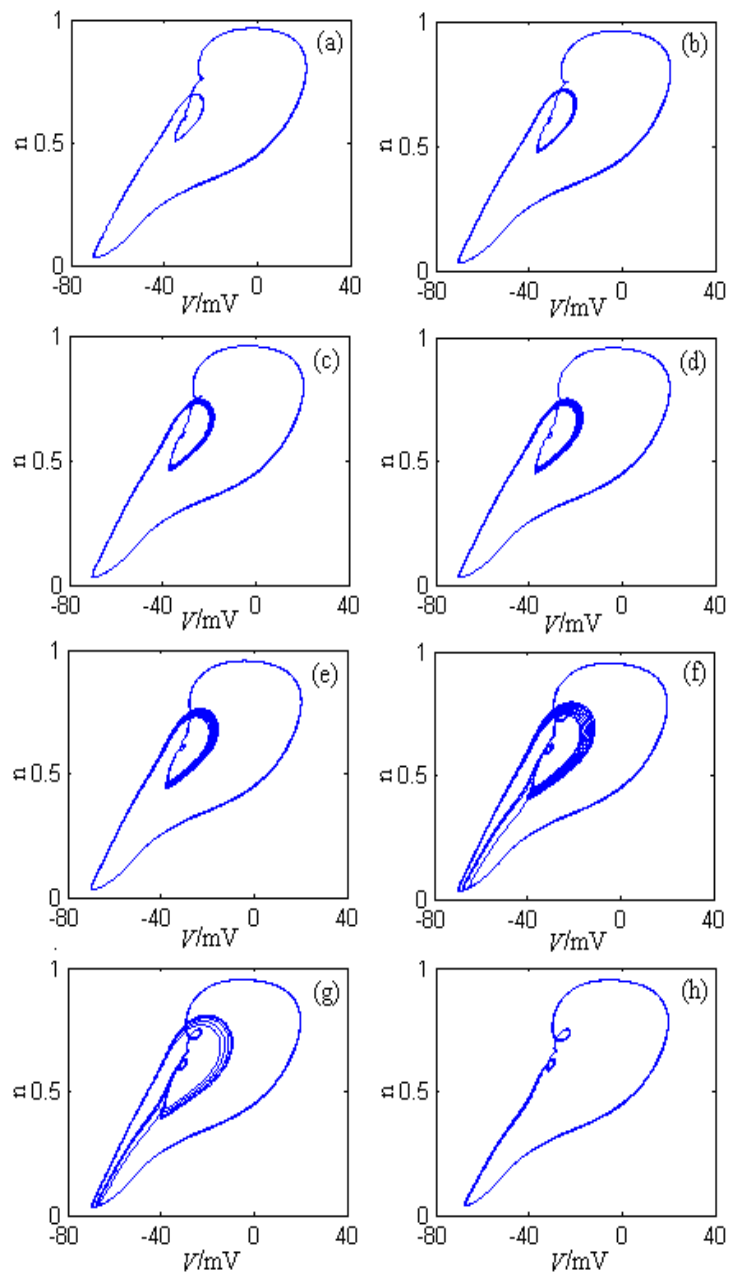

Figure 5. The neuron model's attractors' changing process on V-n phase plane, where $g_{K d r}$ is $1.2 \sim 1.7 \mathrm{mS} / \mathrm{cm}^{2}$. (a) $g_{K d r}=1.2 \mathrm{mS} / \mathrm{cm}^{2}$. (b) $g_{K d r}=1.3 \mathrm{mS} / \mathrm{cm}^{2}$. (c) $g_{K d r}=1.4 \mathrm{mS} / \mathrm{cm}^{2}$. (d) $g_{K d r}=1.45 \mathrm{mS} / \mathrm{cm}^{2}$. (e) $g_{K d r}=1.5 \mathrm{mS} / \mathrm{cm}^{2}$. (f) $g_{K d r}=1.6 \mathrm{mS} / \mathrm{cm}^{2}$. (g) $g_{K d r}=1.65 \mathrm{mS} / \mathrm{cm}^{2}$. (h) $g_{K d r}=1.7 \mathrm{mS} / \mathrm{cm}^{2}$.

From Fig.6, when $g_{K d r}$ is $2.75 \mathrm{mS} / \mathrm{cm}^{2}$, the neuron model's discharge pattern is the chaos; With $g_{K d r}$ 's increasing gradually, the orbits in the chaos attractor region gradually coalesce and annihilate each other; When $g_{K d r}$ is near $2.85 \mathrm{mS} / \mathrm{cm}^{2}$, the chaos attractor becomes the limit cycle of period 2, and the neuron model goes into the period 2 discharge pattern. With 
$g_{K d r}$ 's continually increasing, the inner limit cycle is instable and gradually closes to the outward stable limit cycle; When $g_{K d r}$ is near $3.15 \mathrm{mS} / \mathrm{cm}^{2}$, the two limit cycles fold and become a limit cycle, and the neuron model evolves from the period 2 discharge pattern to the period 1 discharge pattern via the adverse adding period bifurcation.
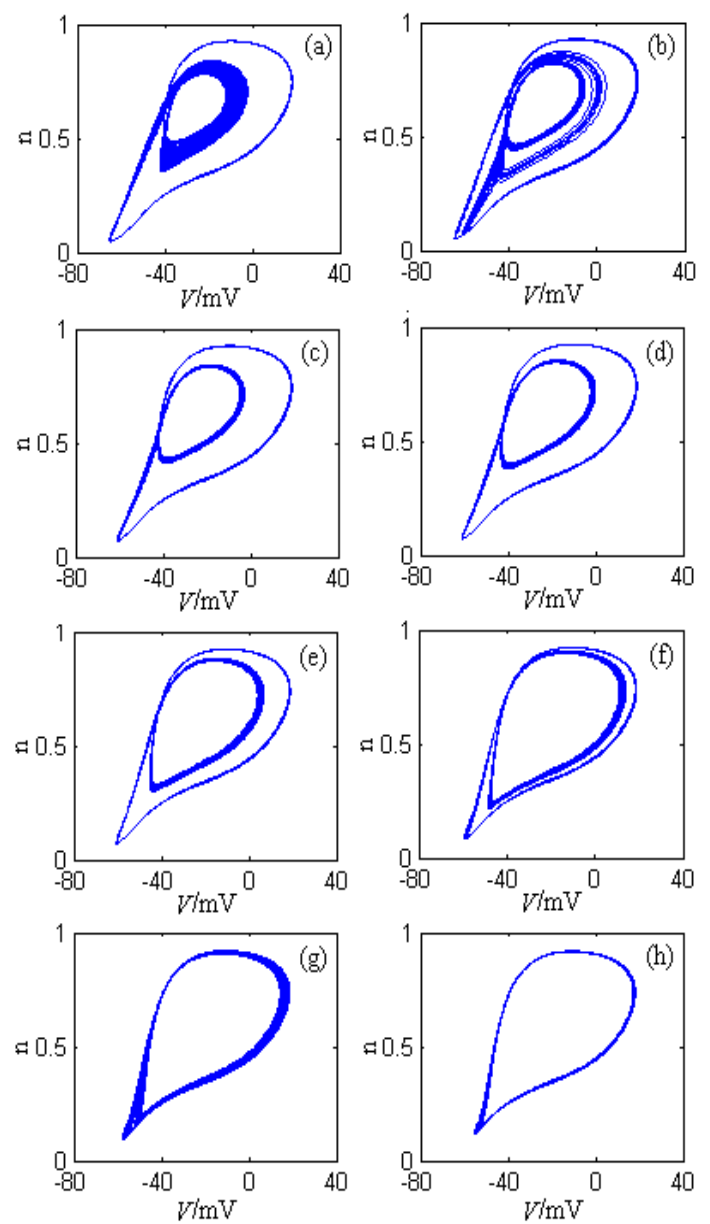

Figure 6. The neuron model's attractors' changing process on V-n phase plane, where $g_{K d r}$ is $2.75 \sim 3.3 \mathrm{mS} / \mathrm{cm}^{2}$. (a) $g_{K d r}=2.75 \mathrm{mS} / \mathrm{cm}^{2}$.

(b) $g_{K d r}=2.8 \mathrm{mS} / \mathrm{cm}^{2}$. (c) $g_{K d r}=2.85 \mathrm{mS} / \mathrm{cm}^{2}$. (d) $g_{K d r}=2.9 \mathrm{mS} / \mathrm{cm}^{2}$.

(e) $g_{K d r}=3.0 \mathrm{mS} / \mathrm{cm}^{2}$. (f) $g_{K d r}=3.1 \mathrm{mS} / \mathrm{cm}^{2}$. (g) $g_{K d r}=3.15 \mathrm{mS} / \mathrm{cm}^{2}$. (h) $g_{K d r}=3.2 \mathrm{mS} / \mathrm{cm}^{2}$.

\section{CONCLUSION}

The hippocampal CA1 pyramid neuron has plenty of discharge actions, and can generate many discharge patterns such as period, the chaos, and so on. Under the certain amplitude current's stimulation, the change of $g_{N a}$ (the maximum conductance of the transient sodium channel) and $g_{K d r}$ (the maximum conductance of the delay rectification potassium channel) can cause different dynamic characteristics of the neuron model. The transient $\mathrm{Na}^{+}$current $\left(I_{N a}\right)$ caused by $g_{N a}$ is indispensable in the discharge's formation process of the model. The model can generate the discharge process only when $g_{N a}$ reaches a certain threshold. In addition, $g_{\mathrm{Na}}$ 's changing affects little in the discharge process of the neuron model, and the ISIs approximate to a straight line; That is to say, the discharge frequency keeps unchanged. The delay rectification $\mathrm{K}^{+} \operatorname{current}\left(I_{K d r}\right)$ caused by $g_{K d r}$ isn't indispensable in the discharge's formation process of the model. But $g_{K d r}$ 's changing affects much in the discharge process of the neuron model. With $g_{K d r}$ 's changing, the neuron model undergoes different dynamic bifurcation process, and has plenty of discharge patterns, and these discharge patterns mainly include the chaos, period, and so on.

This investigation is helpful to know and investigate deeply the dynamic characteristics and the bifurcation mechanism of the hippocampal neuron; and it provides a certain theory assist to investigate the neural diseases such as the Alzheimer disease by the neurodynamics.

\section{APPENDIX A}

Parameters' values of the nine-dimension onecompartment complex model of CA1 pyramid neuron developed by David are as follow:

$$
\begin{aligned}
& C=1 u F / \mathrm{cm}^{2} \text {; } \\
& g_{L}=0.05 \mathrm{mS} / \mathrm{cm}^{2} \text {; } \\
& V_{L}=-70 m V \text {; } \\
& g_{N a}=35 \mathrm{mS} / \mathrm{cm}^{2} \text {; } \\
& g_{N a P} \text { is about } 0 \sim 0.41 \mathrm{mS} / \mathrm{cm}^{2} \text {; } \\
& g_{K d r}=6 \mathrm{mS} / \mathrm{cm}^{2} \text {; } \\
& g_{A}=1.4 \mathrm{mS} / \mathrm{cm}^{2} \text {; } \\
& g_{M}=1 \mathrm{mS} / \mathrm{cm}^{2} \text {; } \\
& V_{N a}=55 \mathrm{mV} \text {; } \\
& V_{K}=-90 m V \text {; } \\
& g_{C a} \text { is about } 0 \sim 0.2 \mathrm{mS} / \mathrm{cm}^{2} \text {; } \\
& g_{y}=10 \mathrm{mS} / \mathrm{cm}^{2} \text {; } \\
& g_{\text {SAHP }}=5 \mathrm{mS} / \mathrm{cm}^{2} \text {; } \\
& V_{C a}=120 m V \text {; } \\
& m_{\infty}(V)=\frac{1}{1+\exp \left(\frac{-30-V}{9.5}\right)} ; \\
& p_{\infty}(V)=\frac{1}{1+\exp \left(\frac{\theta_{p}-V}{3}\right)} \\
& -47 m V \leq \theta_{p} \leq-41 m V ; \\
& a_{\infty}(V)=\frac{1}{1+\exp \left(\frac{-50-V}{20}\right)} ;
\end{aligned}
$$




$$
\begin{aligned}
& d_{\infty}\left(\left[C a^{2+}\right]_{i}\right)=\frac{1}{1+\frac{6}{\left[C a^{2+}\right]_{i}}} ; \\
& h_{\infty}(V)=\frac{1}{1+\exp \left(\frac{-45-V}{-7}\right)} \text {; } \\
& \tau_{h}(V)=0.1+0.75 \times \frac{1}{1+\exp \left(\frac{-40.5-V}{-6}\right)} ; \\
& n_{\infty}(V)=\frac{1}{1+\exp \left(\frac{-35-V}{10}\right)} \\
& \tau_{n}(V)=0.1+0.5 \times \frac{1}{1+\exp \left(\frac{-27-V}{-15}\right)} \text {; } \\
& b_{\infty}(V)=\frac{1}{1+\exp \left(\frac{-80-V}{-6}\right)} ; \\
& \tau_{b}=15 \mathrm{~ms} \text {; } \\
& z_{\infty}(V)=\frac{1}{1+\exp \left(\frac{-39-V}{5}\right)} ; \\
& \tau_{z}=75 m s ; \\
& r_{\infty}(V)=\frac{1}{1+\exp \left(\frac{-20-V}{10}\right)} ; \\
& \tau_{r}=1 m s \\
& y_{\infty}(V)=\frac{1}{1+\exp \left(\frac{-30-V}{7}\right)} ; \\
& \tau_{y}=2 m s ; \\
& \tau_{q}=450 \mathrm{~ms} \text {; } \\
& v=0.13 \mathrm{~cm}^{2} /(m s \times \mu A) \text {; } \\
& q_{\infty}\left(\left[\mathrm{Ca}^{2+}\right]_{i}\right)=\frac{1}{1+\frac{16}{\left[C a^{2+}\right]_{i}^{4}}} ; \\
& \tau_{C a}=13 m s \text {; }
\end{aligned}
$$

\section{ACKNOWLEDGMENT}

The authors would like to thank "The 2nd International Conference on Biomedical Engineering and Computer Science (ICBECS 2011)" for providing the chance and really appreciate the anonymous reviewers for the valuable comments on the paper.

\section{REFERENCES}

[1] Urbani A and Belluzzi O, "Riluzole inhibits the persistent sodium current in mammalian CNS neurons," Eur $J$ Neurosci, vol. 12, pp. 3567-3574, January 2000.
[2] Vasilyev DV and Barish ME, "Postnatal development of the hyperpolarization-activated excitatory current Ih in mouse hippocampal pyramidal neurons," J Neurosci, vol. 22, pp. 8992-9004, April 2002.

[3] Vervaeke $\mathrm{K}, \mathrm{Hu} \mathrm{H}$, Graham LJ, and Storm JF, "Contrasting effects of the persistent Na_current on neuronal excitability and spike timing,” Neuron, vol. 49, pp. 257-270, May 2006.

[4] Shuai J, Bikson M, Hahn PJ, Lian J, and Durand DM, "Ionic mechanisms underlying spontaneous CA1 neuronal firing in Ca2+-free solution,” Biophys J, vol. 84, pp. 20092011, April 2003.

[5] Gu N, Vervaeke K, Hu H, and Storm JF, "Kv7/KCNQ/M and $\mathrm{HCN} / \mathrm{h}$, but not KCa2/SK channels, contribute to the somatic medium after-hyperpolarization and excitability control in CA1 hippocampal pyramidal cells,” J Physiol, vol. 566, pp. 689-715, June 2005.

[6] Chen S, Yue C, and Yaari Y, "A transitional period of calcium-dependent bursting triggered by spike backpropagation into apical dendrites in developing hippocampal neurons,” J Physiol, vol. 567, pp. 79-93, March 2005.

[7] Metz AE, Jarsky T, Martina M, and Spruston N, "R-type calcium channels contribute to afterdepolarization and bursting in hippocampal CA1 pyramidal neurons," $J$ Neurosci, vol. 25, pp. 5763-5773, April 2005.

[8] Traub RD, Wong RK, Miles R, and Michelson H, "A model of a CA3 hippocampal pyramidal neuron incorporating voltage-clamp data on intrinsic conductances," J Neurophysiol, vol. 66, pp. 635-649, 1991.

[9] Traub RD and Miles R, "Neuronal networks of the hippocampus,” New York: Cambridge, 1991.

[10] Traub RD, Jefferys JGR, Miles R, Whittington MA, and To'th K , "A branching dendritic model of a rodent CA3 pyramidal neurone,” J Physiol, vol. 481, pp. 79-95, February 1994.

[11] Warman EN, Durand DM, and Yuen GL, "Reconstruction of hippocampal CA1 pyramidal cell electrophysiology by computer simulations," J Neurophysiol, vol. 71, pp. 20332045, April 1994.

[12] Yue C, Remy S, Su H, Beck H, and Yaari Y, "Proximal persistent $\mathrm{Na}+$ channels drive spike afterdepolarizations and associated bursting in adult CA1 pyramidal cells," $J$ Neurosci, vol. 25, pp. 9704-9720, 2005.

[13] Yue C and Yaari Y, "KCNQ/M channels control spike afterdepolarization and burst generation in hippocampal neurons,” J Neurosci, vol. 24, pp. 4614-4624, 2004.

[14] Yue C and Yaari Y, "Axo-somatic and apical dendritic Kv7/M channels differentially regulate the intrinsic excitability of adult rat CA1 pyramidal cells,” $J$ Neurophysiol, vol. 95, pp. 3480-3495, April 2006.

[15] David Golomb, Cuiyong Yue, and Yoel Yaari, "Contribution of Persistent Na+ Current and M-Type K+ Current to Somatic Bursting in CA1 Pyramidal Cells: Combined Experimental and Modeling Study,” $J$ Neurophysiol, vol. 96, pp. 1912-1926, 2006.

[16] Berger TW, "Long-term potentiation of hippocampal synaptic transmission affects rate of behavioral learning," Science, vol. 224, pp. 627-630, 1984.

[17] Xiao MY, Zhuo Q and Nicoll RA, "Metabotropic glutamate receptor activation causes a rapid redistribution of AMPA receptors," Neuropharmacology, vol.41, pp. 664-671, June 2001.

[18] Mellentin C and Abraham WC, "Priming stimulation of group II metabotropic glutamate receptors inhibits the subsequeng induction of rat hippocampal long-term 
depression in vitro,” Neurosci Lett, vol.307, pp.13-16, January 2001.

[19] Hammarstrom AK, Gage PW, "Hypoxia and persistent sodium current,” Eur Biophys J, Vol.31, pp. 323-330, 2002.

[20] Horn EM, waldrop TG, "Hypoxic augmentation of fast2inactivating and persistent sodium currents in rat caudalhypothalamic neurons," J Neurophysiol, vol. 84, pp. 2572-2581, 2000.

[21] R. M. Ghigliazza and P. Holmes, "Minimal models of bursting neurons: How multiple current, conductances and timescales affect bifurcation diagrams," SIAM Journal on Applied Dynamical Systems, 2004.

[22] Miaoxing Yao and Fangqi Chen, "Mathematical Foundation of Nonlinear Theory," Tianjin: Tianjin University Press, 2005.

[23] Eugene M.Izhikevich, "Dynamical Systems in Neuroscience: The Geometry of Excitability and Bursting,” The MIT Press, 2005.

[24] Izhikevich E. M. and Hoppensteadt F.C., "Polychronous Wavefront Computations," International Journal of Bifurcation and Chaos, vol.19, pp. 1733-1739, 2009.

[25] Szatmary B. and Izhikevich E. M., "Spike-Timing Theory of Working Memory,” PLoS Computational Biology, vol.6, pp. e1000879, Auguest 2010.

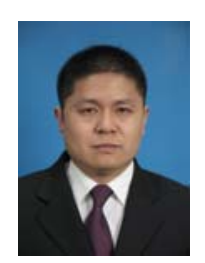

Yueping Peng was born in on 10 February, 1974. he got the Ph.D degree in Biomedical Engineering of Xi'an Jiaotong University in 2010. He received the B.S. degree in Communication Engineering and M.S. degree in Information Engineering, both from Engineering College of Armed Police Force, in
1997 and 2003, respectively. Now he is a member of China Association of Rehabilitation of Disabled Persons and of China Association of Biomedical Engineering. He is a professor, communication engineering department, Engineering College of Armed Police Force. He has pubilished over sixty papers in some science journals and joined thirteen research projects. His research interests are in the dynamic mechanism of neurons' injury and rehabilitation, the signal and information processing, and the neurodynamics and Its application.

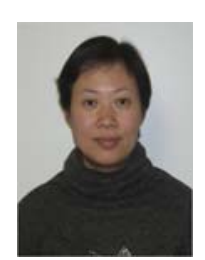

Nan Zou was born in Shaanxi on 23 September, 1975. She received the B.S. degree and the M.S. degree in Law, both from Northwest University, in 1998 and 2006, respectively. Now she is a teacher, the basic department, Engineering College of Armed Police Force. She has pubilished over twenty papers in some science journals and joined eight research projects. Her research interests are in the law application.

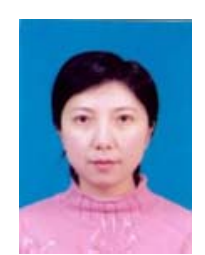

Haiying Wu was born in Shaanxi on 24 December, 1975. She obtained bachelor degree in July 1999 and graduated from Department of Computer Science in Northwestern University at Xi'an Shaanxi China. She obtained master degree in July 2006 and graduated from college of Computer Science in Shaanxi Normal University. Now she is a teacher in Engineering College of Armed Police Force. She has pubilished over thirty papers in some science journals and joined six research projects. The main field of study is Access Control of information security and Artificial Intelligence. 